\title{
BMJ Open Trends in drug poisoning deaths, by sex, in Ireland: a repeated cross-sectional study from 2004 to 2017
}

\author{
Ena Lynn (D) , ${ }^{1,2,3}$ Gráinne Cousins (D) , ${ }^{3}$ Suzi Lyons, ${ }^{1}$ Kathleen E Bennett (1) ${ }^{4}$
}

To cite: Lynn E, Cousins G, Lyons S, et al. Trends in drug poisoning deaths, by sex, in Ireland: a repeated cross-sectional study from 2004 to 2017. BMJ Open 2021;11:e048000. doi:10.1136/ bmjopen-2020-048000

- Prepublication history and additional supplemental material for this paper are available online. To view these files, please visit the journal online (http://dx.doi.org/10.1136/ bmjopen-2020-048000).

Received 14 December 2020 Accepted 16 August 2021

Check for updates

(c) Author(s) (or their employer(s)) 2021. Re-use permitted under CC BY-NC. No commercial re-use. See rights and permissions. Published by BMJ.

${ }^{1}$ National Health Information Systems, Health Research Board, Dublin 2, Ireland ${ }^{2}$ Division of Population Health Sciences, Royal College of Surgeons in Ireland, Dublin, Ireland

${ }^{3}$ School of Pharmacy and Biomolecular Sciences, Royal College of Surgeons in Ireland, Dublin, Ireland

${ }^{4}$ Data Science Centre, Division of Population Health Sciences, Royal College of Surgeons in Ireland, Dublin, Ireland

Correspondence to

Ena Lynn; elynn@hrb.ie

\section{ABSTRACT}

Objective To examine sex differences in age-standardised rates (ASR) of overall and drug-specific drug poisoning deaths in Ireland between 2004 and 2017.

Design Repeated cross-sectional study.

Setting Drug poisoning deaths in Ireland.

Participants National Drug-Related Deaths Index and pharmacy claims database (Primary Care Reimbursement Service-General Medical Services) data from 2004 to 2017.

Outcome measures The primary outcome was trends in drug poisoning death rates by sex. The secondary outcomes were trends in drug poisoning death rates involving (1) any CNS (Central Nervous System) depressants, (2) $\geq 2$ CNS depressants and (3) specific drugs/drug classes (eg, prescription opioids, benzodiazepines, antidepressants, alcohol, cocaine and heroin) by sex. Joinpoint regression was used to examine trends, stratified by sex, in the ASR of drug poisoning deaths (2004-2017), change points over time and average annual percentage changes (AAPCs) with $95 \% \mathrm{Cl}$.

Results Increased ASR for all drug poisoning deaths from 6.86 (95\% Cl 6.01 to 7.72 ) per 100000 in 2004 to 8.08 (95\% Cl 7.25 to 8.91) per 100000 in 2017 was mainly driven by increasing deaths among men (AAPC 2.6\%, 95\% $\mathrm{Cl} 0.2$ to 5.1), with no significant change observed among women. Deaths involving $\geq 2$ CNS depressants increased for both men (AAPC 5.6\%, 95\% Cl 2.4 to 8.8) and women (AAPC 4.0\%, 95\% $\mathrm{Cl} 1.1$ to 6.9). Drugs with the highest significant AAPC increases for men were cocaine $(7.7 \%$, $95 \% \mathrm{Cl} 2.2$ to 13.6$)$, benzodiazepines $(7.2 \%, 95 \% \mathrm{Cl} 2.9$ to 11.6$)$, antidepressants $(6.1 \%, 95 \% \mathrm{Cl} 2.4$ to 10.0$)$ and prescription opioids $(3.5 \%, 95 \% \mathrm{Cl} 1.6$ to 5.5$)$. For women, the highest AAPC was for antidepressants $(4.2 \%, 95 \% \mathrm{Cl}$ 0.2 to 8.3$)$, benzodiazepines $(3.3 \%, 95 \% \mathrm{Cl} 0.1$ to 6.5$)$ and prescription opioids $(3.0 \%, 95 \% \mathrm{Cl} 0.7$ to 5.3$)$.

Conclusion Drugs implicated in drug poisoning deaths vary by sex. Policy response should include prescription monitoring programmes and practical harm reduction information on polydrug use, especially CNS depressant drugs.

\section{INTRODUCTION}

Drug poisonings are a leading cause of avoidable death worldwide, with rates increasing globally. National trends from the USA show that drug poisoning deaths have increased rapidly in recent years, with a $15 \%$ increase

\section{Strengths and limitations of this study}

- The National Drug-Related Deaths Index incorporates national data from four different sources, providing more robust and complete data on drug poisoning deaths.

- Use of mortality data in addition to prescription data enabled assessment of the relationship between trends in prescribing and poisoning deaths involving specific drugs.

- Limitations of this study include the reliance on individual coroners to implicate specific drugs in poisoning deaths, which can be challenging when multiple drugs are present on a toxicology report.

- Information on whether the drugs were prescribed for the individual is frequently not available in the sources of data, which limits the assessment of illicit use of these drugs and the impact of illicit drugs on these deaths.

- Lack of data on private prescription drugs dispensed, stratified by sex, limits analysis to those dispensed through the government-assisted drug payment scheme.

per year between 2013 and 2017. ${ }^{1}$ During this period drug poisoning death rates increased in most US states, primarily due to synthetic opioids. ${ }^{2}$ Drug poisoning deaths involving psychostimulants, especially cocaine, have also increased in the USA. ${ }^{34}$ Accidental drug poisonings are predicted to be a leading cause of premature deaths in the USA over the next decade, especially among women. ${ }^{5}$ Drug poisoning deaths have also increased in Australia since 2006, with opioids being the most common drug group involved in these deaths. ${ }^{6}$

Similar patterns have been observed across Europe. For example, the number of drug poisoning deaths recorded in England and Scotland in 2017 was the highest ever recorded, with opioid-related deaths representing the leading cause of these deaths. ${ }^{7}$ The European Monitoring Centre for Drugs and Drug Addiction (EMCDDA) also reported an increase in drug poisoning deaths between 
2012 and 2018 in Europe, increasing from an estimated 17 deaths per million population aged 15-64 years in $2012,{ }^{8}$ to 22.6 deaths per million population aged $15-64$ years in 2018. ${ }^{9}$ Opioids (both licit and illicit), commonly heroin, are involved in approximately 8 out of every 10 drug poisoning deaths reported in Europe. ${ }^{9}$ However, postmortem toxicology analyses of poisoning deaths suggest that multiple drug toxicity is implicated in most deaths. ${ }^{9}$

While sex differences in drug poisoning deaths have emerged in recent years ${ }^{10}$ most of the available evidence fails to account for variation by sex regarding drugs involved. ${ }^{11}$ Consequently, as drug poisoning deaths are dominated by men, specific circumstances associated with drug poisoning deaths among women may be masked by combining trends for men and women. For example, in the USA, a higher risk of drug poisoning death among young men relative to young women has been reported to be attributed to heroin and synthetic drugs. ${ }^{10}$ In contrast, in both the USA and Scotland, the risk of drug poisoning deaths among older women was attributed to prescription opioids, antidepressants ${ }^{12}{ }^{13}$ and unspecified drugs. ${ }^{10}$ Many drug poisoning deaths involve a fatal cocktail of CNS (Central Nervous System) depressant drugs. ${ }^{14} 15$ Sex-specific differences in pharmacokinetics for CNS depressant drugs such as opioids, ${ }^{16}$ pregabalin and benzodiazepines ${ }^{17}$ suggest that these drugs may be impacting more on polydrug poisoning deaths among women.

Furthermore, although the absolute number of drug poisoning deaths is higher in men, epidemiological trends in Europe and the USA suggest the rate of drug poisoning deaths among women is increasing at a higher rate relative to men, ${ }^{918} 19$ especially in relation to intentional drug poisoning deaths. ${ }^{20}$

The aim of this study is to examine sex differences in age-standardised rates (ASR) of overall drug poisoning deaths and drug poisoning deaths involving (1) any CNS depressants, (2) $\geq 2 \mathrm{CNS}$ depressants and (3) specific drugs/drug classes (eg, prescription opioids, benzodiazepines, antidepressants, alcohol, cocaine and heroin) in Ireland between 2004 and 2017.

This study also examines the association between dispensing rates of prescribed medications commonly implicated in drug poisoning deaths (specifically benzodiazepines and antidepressants) and drug poisoning deaths involving these agents.

\section{METHODS}

The Strengthening the Reporting of Observational Studies in Epidemiology checklist for cross-sectional studies $^{21}$ was used as a guide to structure this repeated cross-sectional study.

\section{Patient and public involvement}

No patients were involved in the design or conduct of the study.

\section{Data sources}

\section{Drug poisoning deaths}

This repeated cross-sectional study includes anonymised individual-level data on all drug poisoning deaths in Ireland as recorded by the National Drug-Related Deaths Index (NDRDI) for years of death from 2004 to 2017 inclusive. The NDRDI is an epidemiological database which records all poisoning deaths by drugs and/or alcohol. ${ }^{22}$ It follows the EMCDDA standard protocol to collect data on drug-related deaths. ${ }^{23}$ To ensure completeness, data from several sources are collected and crosschecked to avoid duplication. Coronial files are the main data source for the NDRDI. Coronial data are collected for the purpose of death investigation, not primarily for research. However, coronial data have been recognised as a rich source of data for monitoring drug poisoning deaths. ${ }^{24}$ Other NDRDI data sources include the general mortality register (via the Central Statistics Office), acute hospitals data (via the Hospital In-Patient Enquiry System) and the national opioid agonist treatment (OAT) register (via the Central Treatment List). Further details on the NDRDI methodology can be found elsewhere. ${ }^{22}$ The methodology for collecting poisoning deaths did not change over the study period.

The NDRDI's definition of a poisoning death is a death directly due to the toxic effect of one or more drugs (including alcohol) on the body, as recorded by the coroner on the certificate of death registration and/or the record of verdict. Up to six drugs implicated in drug poisoning deaths by the coroner can be included in the NDRDI. Data on deaths, which included specific drugs and drug groups, including opioids, benzodiazepines, antidepressants, Z-drugs (zopiclone and zolpidem), pregabalin, alcohol and cocaine, were extracted from the NDRDI for this study. These are the main drugs implicated in poisoning deaths in Ireland. ${ }^{15}$

\section{Pharmacy claims data}

Aggregate-level (by age, sex, year and drug class) pharmacy claims data on prescription drugs, including benzodiazepines and antidepressants, were available from the Irish Health Service Executive (HSE) Primary Care Reimbursement Service (PCRS). This included only those with full eligibility for the General Medical Services (GMS) scheme at any time during 2004-2017 inclusive. Eligibility for the GMS is mainly through means-testing and age; therefore, it over-represents the more socially deprived, younger and older-aged populations in Ireland.

The HSE Primary Care Reimbursement ServiceGeneral Medical Services (PCRS-GMS) pharmacy claims database funds the majority of pharmaceutical expenditure. ${ }^{25}$ It contains details of all prescription medications dispensed to GMS eligible patients in primary care but does not include data on private prescriptions dispensed or hospital prescriptions. However, the PCRS-GMS pharmacy claims database represents the single largest pharmacy claims data set in Ireland. All claims are coded using the WHO's Anatomical Therapeutic Chemical 
Classification. The PCRS-GMS database contains basic demographic information including age, sex and region of residence. ${ }^{25}$ As of 2015 , almost $40 \%$ of the Irish population were covered by the GMS scheme. ${ }^{25}$

Data on all eligible individuals $\geq 16$ years of age who were prescribed benzodiazepines (N05CD, N05BA or N03AE01) and/or antidepressants (N06AA, N06AB, N06AF, N06AG or N06AX) were extracted from the PCRS-GMS database and included in the study. While the PCRS-GMS database records prescription opioids, it does not record methadone or buprenorphine prescriptions for the treatment of opioid dependency. Therefore, the available data on opioids were considered incomplete for the purpose of this study.

\section{Study variables}

The primary outcome was drug poisoning deaths, defined as a death directly due to the toxic effect of one or more drugs (including alcohol) on the body, by sex. The secondary outcomes of interest were drug poisoning deaths involving (1) any CNS depressant drugs, (2) $\geq 2$ CNS depressants drugs and (3) specific drugs/drug classes (prescribed opioids, benzodiazepines, antidepressants, alcohol, cocaine and heroin) by sex. If multiple drugs were implicated in an individual death, then this death can be included in multiple drug categories.

For poisoning deaths involving CNS depressant drugs, any death involving at least one drug from the following drug categories were combined into deaths due to "any CNS depressant drug': opioids (ICD-10 (International Classification of Diseases-10th revision) codes T40.2, T40.3, T40.4 and T40.6), benzodiazepines (ICD-10 code T42.4), alcohol (ICD-10 code T51), pregabalin and/ or Z-drugs (ICD-10 code T42.6, with specific individual NDRDI drug codes for pregabalin, zolpidem and zopiclone identified). Sex, year of death and age groups (15-29, 30-44, 45-59 and $\geq 60$ years) were also included.

\section{Statistical analysis}

All analyses of trends were examined overall and separately for men and women.

\section{Drug poisoning deaths}

Irish general population estimates were extracted from the Central Statistics Office for calculation of rates of drug poisoning deaths per 100000 population. ${ }^{26}$ For prescription rates the GMS eligible population for those aged 16 years and older was extracted from the PCRS annual reports. ${ }^{27}$ The European Standard Population (ESP) was used to calculate ASR. ${ }^{28}$

Trends in age-standardised mortality rates (ASMR) for all drug poisoning deaths and the specific drug groups mentioned above were examined by sex while adjusting for age. Mortality rates for each year of the study period were calculated per 100000 of the general population based on national census and projected population figures ${ }^{26}$ standardised to the ESP. ${ }^{28}$ Rate ratios of ASMR for men compared with women were calculated and
95\% CI computed using the delta method for the variance. Joinpoint Regression Program V.4.8.0.1 ${ }^{29}$ was used to examine any changes in trends in ASR from 2004 to 2017, expressed as annual percentage changes (APCs), with a summary of the overall trend expressed as an average annual percentage change (AAPC). The AAPC is a summary measure which describes the average of the APCs over time. Joinpoint regression detects if there are any statistically significant trend changes in the overall drug poisoning death rates over time, drug poisoning death rates involving any CNS depressant drugs, $\geq 2 \mathrm{CNS}$ depressants drugs and for each of the drugs/drug classes described. Time periods for change in APCs were permitted to vary according to whether or not there were statistically significant change points. A change point is a specific time point where a statistically significant trend change occurred (or a change in the APC). The APCs and the overall AAPCs are presented in the tables with results displayed by sex.

\section{Association with prescribing patterns}

Age-standardised prescription rates (ASPR) per 1000 of GMS eligible population for each calendar year were standardised using the relevant age categories from the ESP.

Ecological analysis of the aggregated data, using annual ASR for drug poisoning deaths and prescription data, was performed using linear regression to examine the relationship (beta regression coefficient, 95\% CI) between trends in ASPR for benzodiazepines and antidepressants. Analyses were stratified by sex.

Statistical significance at $\mathrm{p}<0.05$ was assumed. Data were analysed using Joinpoint Regression Program (V.4.8.0.1; National Cancer Institute, USA) and SPSS V.22.

\section{RESULTS}

\section{All drug poisoning deaths}

For the study period 2004-2017 there were 4993 drug poisoning deaths recorded in Ireland. In 2004 there were 266 drug poisoning deaths (175 (66\%) men; 91 (34\%) women), representing an ASMR of 6.86 deaths per 100000 (8.5 ASMR per 100000 men and 5.0 ASMR per 100000 women). By 2017 there were 376 drug poisoning deaths, an increase of 41.4\% (263 (70\%) men; $113(30 \%)$ women), representing an ASMR of 8.08 per 100000 (11.5 ASMR per 100000 men and 4.8 ASMR per 100000 women). The rate of all drug poisoning deaths among men from 2004 to 2017 increased at an AAPC of $2.6 \%$ (95\% CI 0.2 to 5.1) (table 1). However, there was no significant change among women for the same period (table 2). Joinpoint regression analysis identified an accelerated increase in drug poisoning deaths among men in earlier years (2004-2007), with no significant change in the latter years (2007-2017) (table 1).

The ASMRs for 2004 and 2017 by any CNS depressant drugs, $\geq 2$ CNS depressant drugs, specific drug classes and specific drugs, stratified by sex, are also presented in table 1 (men) and table 2 (women). 
Table 1 ASR (standardised to the European Standard Population) of drug poisoning deaths, per 100000 of the general population, with APC identified for specific change points and overall AAPC, 2004-2017, among men in Ireland

\section{Men}

\begin{tabular}{|c|c|c|c|c|c|}
\hline \multirow[b]{2}{*}{ Drug group } & \multirow[b]{2}{*}{ Period } & \multicolumn{2}{|c|}{$\begin{array}{l}\text { ASR per } 100000 \text { population at change } \\
\text { points identified* }\end{array}$} & \multirow[b]{2}{*}{ APC, \% (95\% Cl) } & \multirow[b]{2}{*}{ AAPC, $\%(95 \% \mathrm{CI})$} \\
\hline & & Start & End & & \\
\hline \multirow[t]{3}{*}{ All drug poisoning deaths } & 2004-2007 & 8.51 & 11.50 & $13.2(1.6 \text { to } 26.1)^{\star * \star}$ & \\
\hline & 2007-2017 & 11.50 & 11.19 & $-0.3(-1.9$ to 1.2$)$ & \\
\hline & 2004-2017 & 8.51 & 11.19 & & $2.6(0.2 \text { to } 5.1)^{\star \star \star}$ \\
\hline \multirow[t]{3}{*}{ Any CNS depressant drug } & 2004-2008 & 6.91 & 9.75 & $10.1(3.3 \text { to } 17.3)^{\star * \star}$ & \\
\hline & 2008-2017 & 9.75 & 8.57 & $-1.1(-2.7$ to 0.6$)$ & \\
\hline & 2004-2017 & 6.91 & 8.57 & & $2.2(0.3 \text { to } 4.3)^{\star \star \star}$ \\
\hline \multirow[t]{3}{*}{ Two or more CNS depressant drugs } & 2004-2011 & 2.29 & 5.67 & $10.8(5.9 \text { to } 16.0)^{\star \star \star}$ & \\
\hline & 2011-2017 & 5.67 & 4.95 & $-0.2(-5.4$ to 5.3$)$ & \\
\hline & 2004-2017 & 2.29 & 4.95 & & $5.6(2.4 \text { to } 8.8)^{\star \star \star}$ \\
\hline Prescription opioids & 2004-2017 & 2.76 & 3.96 & & $3.5(1.6 \text { to } 5.5)^{\star \star \star}$ \\
\hline Benzodiazepines & 2004-2017 & 1.56 & 3.96 & & $7.2(2.9 \text { to } 11.6)^{\star \star \star}$ \\
\hline Antidepressants & 2004-2017 & 0.70 & 1.50 & & $6.1(2.4 \text { to } 10.0)^{\star \star \star}$ \\
\hline Alcohol & 2004-2017 & 4.12 & 3.83 & & $-0.9(-3.2$ to 1.4$)$ \\
\hline \multirow[t]{4}{*}{ Cocaine } & 2004-2006 & 0.64 & 2.19 & $107.3(56 \text { to } 175.6)^{\star \star \star}$ & \\
\hline & 2006-2010 & 2.19 & 0.64 & $-25.0(-35.1 \text { to }-13.3)^{\star \star \star}$ & \\
\hline & 2010-2017 & 0.64 & 1.58 & $9.9(5.6 \text { to } 14.3)^{\star \star \star}$ & \\
\hline & 2004-2017 & 0.64 & 1.58 & & $7.7(2.2 \text { to } 13.6)^{\star \star \star}$ \\
\hline \multirow[t]{3}{*}{ Heroin } & 2004-2006 & 0.61 & 2.70 & $83.4(-33.7$ to 407.7$)$ & \\
\hline & $2006-2017$ & 2.70 & 2.64 & $-1.1(-4.5$ to 2.5$)$ & \\
\hline & 2004-2017 & 0.61 & 2.64 & & $8.8(-5.2$ to 24.9$)$ \\
\hline
\end{tabular}

The APC was reported for time periods where a statistically significant trend change occurred.

Change point is a specific time period where a statistically significant trend change occurred.

Variables significant at ${ }^{* \star *} \mathrm{p}<0.001$.

*ASR per 100000 population at the start and end of the change points identified and at the start and end of the study period.

AAPC, average annual percentage change; APC, annual percentage change; ASR, age-standardised rate; CNS, Central Nervous System.

\section{CNS depressant drugs}

The rate of drug poisoning deaths involving any CNS depressant drugs increased from an ASMR of 5.61 deaths per 100000 in 2004 to an ASMR of 6.38 per 100000 in 2017 (table 3). There was an AAPC increase of 2.2\% (95\% CI 0.3 to 4.3 ) for men, with an accelerated increase noted for the period 2004-2008. However, when drug poisoning deaths involved $\geq 2$ CNS depressant drugs, men showed a higher AAPC at 5.6\% (95\% CI 2.4 to 8.8) (table 1).

For women who died of drug poisoning involving any CNS depressant drugs, no significant AAPC was observed. However, when $\geq 2$ CNS depressant drugs were involved in the death, there was an AAPC of 4\% (95\% CI 1.1 to 6.9) (table 2).

Benzodiazepines were the main drug group implicated in all (men and women combined) drug poisoning deaths involving $\geq 2$ CNS depressant drugs, implicated in $76 \%$ of these deaths.

\section{Prescription opioids}

All drug poisoning deaths involving prescription opioids, of which $61 \%$ consisted of methadone, have increased over time (table 3), with similar AAPC for both men $(3.5 \%, 95 \%$ CI 1.6 to 5.5$)$ and women $(3.0 \%, 95 \%$ CI 0.7 to 5.3) with no change points, indicating no change in trend(s) within the reporting period noted (tables 1 and 2). Overall, $43 \%(n=477)$ of deaths involving methadone were among people with a history of opioid dependence and registered on the national OAT register, increasing from $35 \% \quad(n=14)$ in 2004 to $52 \% \quad(n=49)$ in 2017. Although fewer women are in receipt of OAT relative to men, almost two in three women $(\mathrm{n}=185,63 \%)$ who had methadone implicated in their death were registered on the OAT register. In contrast, just over one in three $(\mathrm{n}=292,36 \%)$ men, where methadone was implicated in their poisoning death, were registered on the national OAT register. However, it must be noted that clients can remain on the OAT register up to 30 days after dropping out of treatment. Therefore, it is unclear whether these deaths occurred while a person was on or off treatment.

\section{Benzodiazepines}

The rate of drug poisoning deaths involving benzodiazepines increased over the observation period at an AAPC of $7.2 \%$ (95\% CI 2.9 to 11.6) among men (table 1) and $3.3 \%$ (95\% CI 0.1 to 6.5 ) among women (table 2) with no change points, indicating no change in trend(s) within the reporting period, observed for either men or women 
Table 2 ASR (standardised to the European Standard Population) of drug poisoning deaths, per 100000 of the general population, with APC identified for specific change points and overall AAPC, 2004-2017, among women in Ireland

\section{Women}

\begin{tabular}{|c|c|c|c|c|c|}
\hline \multirow[b]{2}{*}{ Drug group } & \multirow[b]{2}{*}{ Period } & \multicolumn{2}{|c|}{$\begin{array}{l}\text { ASR per } 100000 \\
\text { population at change } \\
\text { points identified* }\end{array}$} & \multirow[b]{2}{*}{ APC, \% (95\% Cl) } & \multirow[b]{2}{*}{ AAPC, $\%(95 \% \mathrm{Cl})$} \\
\hline & & Start & End & & \\
\hline All drug poisoning deaths & 2004-2017 & 4.99 & 4.84 & & $-0.5(-2.2$ to 1.2$)$ \\
\hline \multirow[t]{2}{*}{ Any CNS depressant drug } & 2004-2012 & 4.20 & 3.21 & $-0.9(-5.1$ to 3.4$)$ & \\
\hline & 2012-2017 & 3.21 & 3.98 & $1.5(-6.3$ to 9.8$)$ & \\
\hline $\begin{array}{l}\text { Two or more CNS } \\
\text { depressant drugs }\end{array}$ & 2004-2017 & 2.08 & 2.11 & & $4.0(1.1 \text { to } 6.9)^{\star \star \star}$ \\
\hline Prescription opioids & 2004-2017 & 1.54 & 2.02 & & $3.0(0.7 \text { to } 5.3)^{\star \star \star}$ \\
\hline Benzodiazepines & 2004-2017 & 1.70 & 1.67 & & $3.3(0.1 \text { to } 6.5)^{\star \star \star}$ \\
\hline \multirow{3}{*}{ Cocaine } & 2008-2011 & 0.45 & 0.04 & $-56.6(-84.1$ to 18.6$)$ & \\
\hline & 2011-2017 & 0.04 & 0.58 & $53.8(26.0 \text { to } 87.8)^{\star \star *}$ & \\
\hline & $2004-2017$ & 0.08 & 0.58 & & $16.5(-6.3$ to 44.8$)$ \\
\hline Heroin & 2004-2017 & 0.09 & 0.47 & & $7.0(-0.2$ to 14.6$)$ \\
\hline
\end{tabular}

The APC was reported for time periods where a statistically significant trend change occurred.

Change point is a specific time period where a statistically significant trend change occurred.

Variables significant at ${ }^{* \star *} p<0.001$.

*ASR per 100000 population at the start and end of the change points identified and at the start and end of the study period.

AAPC, average annual percentage change; APC, annual percentage change; ASR, age-standardised rate; CNS, Central Nervous System.

(tables 1 and 2). Diazepam was the main benzodiazepine drug involved in these deaths. However, there has been a substantial increase in the number of drug poisoning deaths involving alprazolam in the latter years (online supplemental table 1) for both men and women. In 2004 alprazolam was involved in less than 5 deaths, rising to
63 deaths in 2017, with the majority among men (men: $\mathrm{n}=47,75 \%$; women: $\mathrm{n}=16,25 \%$ ).

For benzodiazepines, a negative relationship was observed between prescribing data and drug poisoning deaths for both men $(\beta=-0.067,95 \%$ CI -0.116 to -0.018 , $\mathrm{p}=0.012)$ and women $(\beta=-0.016,95 \%$ CI -0.031 to 0.000 ,

Table 3 Age-standardised rates (standardised to the European Standard Population) of drug poisoning deaths, per 100000 of the general population, 2004-2017, among all drug poisoning deaths in Ireland and ratio of men to women

\section{Total drug poisoning deaths}

\begin{tabular}{|c|c|c|c|c|}
\hline \multirow[b]{2}{*}{ Drug group } & \multicolumn{2}{|c|}{$\begin{array}{l}\text { Age-standardised rates per } 100000 \text { population } \\
(95 \% \mathrm{Cl})\end{array}$} & \multicolumn{2}{|c|}{ Ratio of men to women $(95 \% \mathrm{Cl})$} \\
\hline & 2004 & 2017 & 2004 & 2017 \\
\hline Any CNS depressant drug & 5.61 (4.84 to 6.38$)$ & $6.38(5.65$ to 7.11$)$ & 1.62 (1.58 to 1.66$)$ & 2.17 (2.14 to 2.19$)$ \\
\hline Two or more CNS depressant drugs & 2.16 (1.69 to 2.63$)$ & 3.56 (3.02 to 4.09$)$ & 1.11 (1.01 to 1.20$)$ & 2.35 (2.29 to 2.40$)$ \\
\hline Prescription opioids & 2.03 (1.61 to 2.46$)$ & 3.01 (2.52 to 3.51$)$ & $1.66(1.56$ to 1.76$)$ & 1.93 (1.86 to 1.99$)$ \\
\hline Antidepressants & $1.28(0.90$ to 1.67$)$ & $1.47(1.14$ to 1.83$)$ & $0.42(0.22$ to 0.62$)$ & $1.06(0.94$ to 1.18$)$ \\
\hline Alcohol & 3.50 (2.87 to 4.14$)$ & 2.79 (2.29 to 3.28$)$ & 1.45 (1.38 to 1.52$)$ & 2.30 (2.23 to 2.38$)$ \\
\hline Cocaine & $0.37(0.21$ to 0.54$)$ & $1.02(0.75$ to 1.30$)$ & 8.36 (7.26 to 9.44$)$ & 2.67 (2.49 to 2.86$)$ \\
\hline Heroin & 0.60 (0.37 to 0.82$)$ & 1.51 (1.17 to 1.85$)$ & $11.72(10.64$ to 12.80$)$ & $6.00(5.83$ to 6.23$)$ \\
\hline
\end{tabular}

CNS, Central Nervous System. 

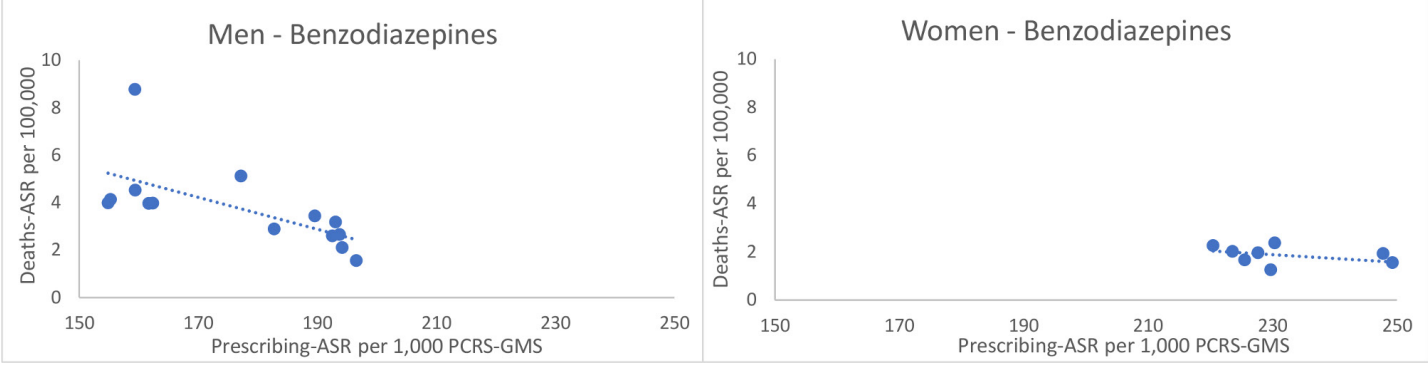

Figure 1 Benzodiazepines: ASR per 100000 of drug poisoning deaths involving benzodiazepines and ASR per 1000 of individuals in receipt of prescribed benzodiazepines through the PCRS-GMR, 2004-2017. ASR, age-standardised rate; PCRSGMR, Primary Care Reimbursement Service-General Medical Services.

$\mathrm{p}=0.044$ ) for the period 2004-2017 (figure 1). However, this relationship was not statistically significant for women.

\section{Antidepressants}

For both men $(6.1 \%, 95 \%$ CI 2.4 to 10.0$)$ and women $(4.2 \%, 95 \%$ CI 0.2 to 8.3$)$, there was a significant increase in the AAPC rates for drug poisoning deaths involving antidepressants (tables 1 and 2). There were no change points, indicating no change in trend(s) within the reporting period observed (tables 1 and 2). Although the ASMR for women in 2017 (1.40 per 100 000) was lower than the rate in 2004 (1.71 per 100000$)$, the yearly rates fluctuated during the reported period with an overall upward trend. This did not result in any significant change points.

For antidepressants, a positive relationship between prescription data and drug poisoning data was observed for both men ( $\beta=0.013,95 \%$ CI 0.003 to $0.022, p=0.011$ ) and women ( $\beta=0.006,95 \%$ CI 0.000 to $0.012, p=0.045$ ) (figure 2). The ASR of antidepressant items dispensed per 1000 of the GMS population increased over the study period for both men (from 153.1 per 1000 in 2004 to 218.6 per 1000 in 2017) and women (from 232.0 per 1000 in 2004 to 336.3 per 1000 in 2017).

\section{Alcohol}

The rate for women who died of drug poisoning involving alcohol decreased with an AAPC decrease of $4.0 \%(95 \%$ CI -5.8 to -2.1 ) between 2004 and 2017 (table 2). There was no statistically significant AAPC in rates for men in the same period (table 1). No significant change points, indicating no change in trend(s) within the reporting period, were observed for men or women. Over half of all drug poisoning deaths involving alcohol were polydrug poisoning deaths $(\mathrm{n}=1889,52.8 \%)$, with similar percentages for men $(\mathrm{n}=685,52.1 \%)$ and women $(\mathrm{n}=312,54.3 \%)$ (online supplemental table 1). Other CNS depressant drugs were implicated in almost a third $(\mathrm{n}=575,30.4 \%)$ of polydrug poisoning deaths involving alcohol. Benzodiazepines were the main other CNS depressant drug group involved in alcohol polydrug poisoning deaths, implicated in one in three drug poisoning deaths involving alcohol $(\mathrm{n}=563,29.8 \%)$.

\section{Cocaine}

Drug poisoning deaths involving cocaine fluctuated over the study period. For men, an accelerated increase was observed during the periods 2004-2006 and 2010-2017, with a significant decrease during the intervening period 2006-2010, giving an overall AAPC increase of 7.7\% (95\% CI 2.2 to 13.6) (table 1). Accelerated increases were also identified among women in the periods 2004-2008 and 2011-2017, but no significant AAPC was observed among women (table 2). Although there is a higher incidence of cocaine-related drug poisoning deaths among men relative to women, the gap between men and women is narrowing, with the ASMR ratio of men to women decreasing from 8.36 in 2004 to 2.67 in 2017 (table 3).
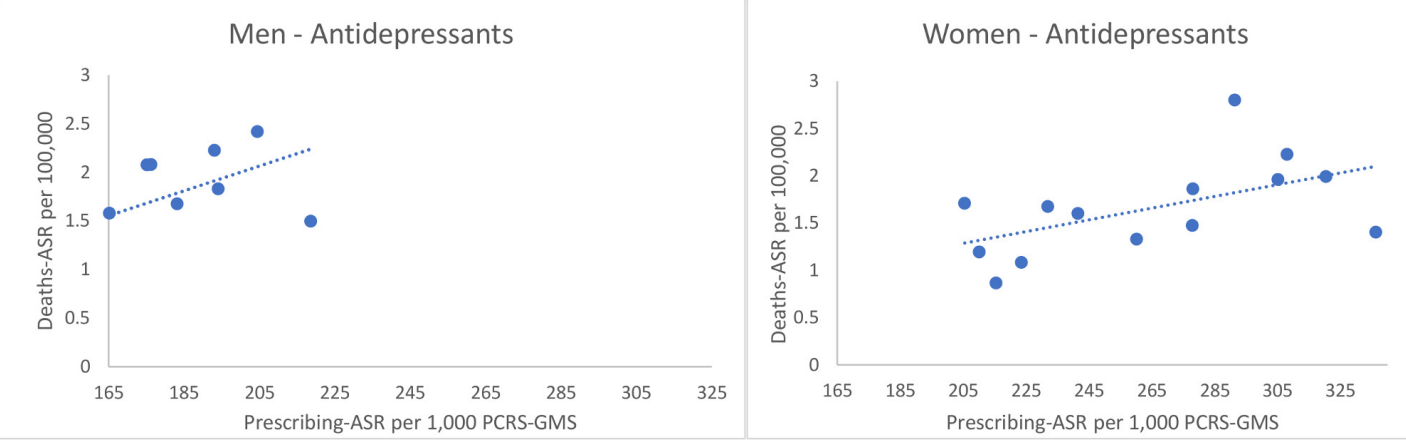

Figure 2 Antidepressants: ASR per 100000 of drug poisoning deaths involving antidepressants and ASR per 1000 of individuals in receipt of prescribed antidepressants through the PCRS-GMS, 2004-2017. ASR, age-standardised rate; PCRSGMS, Primary Care Reimbursement Service-General Medical Services. 


\section{Heroin}

No trend change, for either sex, was observed for drug poisoning deaths involving heroin over the study period (tables 1 and 2). While the incidence of heroin drug poisoning deaths is low among women relative to men, the gap between men and women is decreasing, with the ASMR ratio of men to women decreasing from 11.7 in 2004 to 6.0 in 2017 (table 3).

\section{DISCUSSION}

\section{Summary of findings}

This repeated cross-sectional study found that there was a significant increase in overall drug poisoning deaths in Ireland during the period 2004-2017. The ASMR for drug poisoning deaths increased among men in the early years of the study, with no significant change in the latter stage of the study period. The ASMR for overall drug poisoning deaths among women remained stable.

A similar pattern was found among men when any CNS depressant drug was implicated in poisoning deaths, with a significant increase noted only for earlier years (20042008). In contrast, no significant increase was found for deaths among women involving any CNS depressant drug.

The increasing trend for two or more CNS depressant drugs implicated in drug poisoning deaths, especially the more recent significant increase among women, is of concern. This finding suggests that combinations of CNS depressant drugs may be impacting more on polydrug poisoning deaths in more recent years.

Our study findings differ from that reported in the USA, where prescription opioids including fentanyl are the main drugs driving the increase in drug poisoning deaths. ${ }^{2}$ In Ireland, while drug poisoning deaths involving prescription opioids have increased, deaths involving fentanyl remain very low. ${ }^{15}$ Cocaine, antidepressants and benzodiazepines, especially when combined with other CNS depressant drugs, were observed to have the highest increasing trend in drug poisoning deaths in Ireland.

Our previous research has shown a stronger association of methadone being present as part of a combination of CNS depressant drugs in drug poisoning deaths among women relative to men. ${ }^{30}$ This current study found the majority of deaths involving prescription opioids related to methadone (both prescribed and illicit), similar to findings in the UK, ${ }^{14}$ with women disproportionately affected. Compared with men, a higher percentage of women who died from drug poisoning involving methadone were registered for OAT at the time of their death, even though fewer women receive OAT in Ireland. ${ }^{31}$ A growing body of evidence suggests that mortality risk during OAT is timevarying. ${ }^{32}$ As a full opioid agonist, methadone can cause hazardous respiratory depression and is associated with an elevated risk of drug poisoning during the first 4 weeks of treatment initiation. ${ }^{32-35}$ The treatment timeframe for individuals included in this study is unknown. The risk of drug poisoning mortality immediately following OAT dropout, particularly the first 4 weeks, is also high. ${ }^{33-36}$
Given that clients' treatment status on the OAT register remains active for up to 4 weeks from their first day of non-attendance with their treatment provider, we cannot ascertain whether clients had dropped out of treatment. It is plausible that many clients who died of a drug poisoning death while registered on the OAT register had in fact left treatment because global evidence clearly demonstrates the protective effects of treatment versus leaving treatment. ${ }^{37}$ Future work is necessary to ascertain whether the drugs involved in drug poisoning deaths vary depending on where a client is in terms of their OAT journey at the time of death.

It is imperative that there is increased awareness among prescribers and people who use drugs of the differences between men and women in drug metabolism and drug action, as well as the risks associated with both prescribing and consuming multiple CNS depressant drugs. Benzodiazepines were the most common drug group in poisoning deaths involving two or more CNS depressant drugs; therefore, the combination of benzodiazepines with other CNS depressant drugs warrants further investigation. Polydrug use has been recognised as an area of public health concern and has been described as 'the norm' among people who use drugs. ${ }^{38}$ Polydrug use, especially opioids with sedative drugs, including benzodiazepines, has been associated with active post-traumatic stress disorder ${ }^{39}$ and with serious health risks including drug poisoning deaths. ${ }^{40}$

This study found that for women drug poisoning deaths involving prescription opioids, benzodiazepines and/or antidepressants increased during the study period. This result contributes to a growing body of research highlighting opioids, benzodiazepines and antidepressants as the main drugs involved in drug poisoning deaths among women. ${ }^{11}$

The increased availability of illicit ('street') drugs especially benzodiazepines (including illicit alprazolam and diazepam) and illicit prescription opioids (such as methadone) certainly contributes to drug poisoning deaths. However, the main drugs involved in drug poisoning deaths are prescription drugs which are commonly prescribed, and it is not always recorded in data sources if these drugs were prescribed to the deceased individual. Therefore, increased monitoring of prescribing practices, in addition to enabling and enforcing use of electronic prescriptions, is required. Implementation of a national prescription monitoring system and linkage of NDRDI data to dispensed prescription data would assist in confirming whether drugs involved in drug poisoning deaths were prescribed to the individual or obtained illicitly at the time of death. A national prescription monitoring system would provide important insights into the supply, availability and appropriate prescribing of prescription drugs with potential for misuse in Ireland.

Our study showed a significant association, for both sexes (although marginal for women), between the rate of antidepressants dispensed and the rate of poisoning deaths involving antidepressants. While this does not 
indicate causality, it does suggest a relationship. However, in observational studies of this sort, the possibility of residual confounding may remain a problem. Therefore associations identified in this study should be viewed principally as hypothesis-generating and subject to further testing and verification in future national cohort studies. Men are known to have higher rates of suicide, substance use disorder and neurodevelopment disorders relative to women. ${ }^{41}$ Other mental health issues such as anxiety and depression are reported to be higher among women relative to men; however, this may be as a result of reporting bias among men who tend to mask their symptoms more than women. ${ }^{41}$ Taking this into consideration, the higher rates of prescribing of antidepressants among men may be an indirect indicator of more men seeking medical help for mental health issues. This increase in prescribing correlates with results from a population prevalence study which showed an increasing trend in use of antidepressants among both men and women. ${ }^{42}$ Further research is necessary into the type of antidepressants, both dispensed and implicated in drug poisoning deaths, as well as their impact on suicide deaths by drug poisoning.

Per capita consumption of alcohol has been shown to be an important determinant of alcohol-related deaths, which include drug poisoning deaths. ${ }^{43}$ Per capita consumption of alcohol in Ireland decreased during the study period. ${ }^{44}$ Our results are in line with this as they show a decrease in drug poisoning deaths involving alcohol over the same period, with a significant decrease noted for women. This is a welcome finding and may indicate a relationship between decreased consumption and decreased alcohol poisoning deaths, thus emphasising the need for full implementation of the Public Health (Alcohol) Bill $2018^{45}$ in Ireland. Of note, as alcohol is a CNS depressant, and given the high presence of other CNS depressants in polydrug poisoning deaths involving alcohol, prescribers should assess for and advise on alcohol use when prescribing CNS depressant drugs.

Following an increase in the early years of the study period, rates of drug poisoning deaths involving cocaine decreased for men and women at a time of economic recession in Ireland. ${ }^{46}$ Our findings show that as the economy improved postrecession, there was a significant increase in cocaine-related drug poisoning deaths for both sexes, similar to that seen in other jurisdictions, ${ }^{47}$ with the increase more substantial among women. Results from a national prevalence study during the study period also showed that while there was no significant increase in recent (last month) use of cocaine among men, there was a significant increase in recent use of cocaine among women. ${ }^{42}$ In addition, in recent years there has been an increase in people seeking treatment related to cocaine use, ${ }^{9}$ with an increase in the proportion of women in receipt of treatment for cocaine during the latter years of the study. ${ }^{48}$ This trend highlights the impact of market forces on drug poisoning deaths and reflects the need to extend education and treatment related to cocaine use, especially for women.

\section{Clinical and policy implications}

The increasing trend of CNS depressant drugs involved in drug poisoning deaths may indicate both increased use of these drugs to treat or cope with both substance use disorder and other mental health issues, in addition to inappropriate (including illicit) use of these drugs by individuals in the community.

Increasing awareness in both the treatment settings and in the community of the synergistic effect of taking multiple CNS depressant drugs, including alcohol, is warranted. This should include engagement with advocacy groups who work with people who use drugs to promote dissemination of harm reduction information to harder-to-reach groups, including those who are homeless. In addition, increased awareness among medical practitioners of the physiological sex differences affecting drug activity when prescribing CNS depressant drugs is important. These differences include slower renal clearance of certain CNS depressant drugs, including pregabalin; women being more sensitive to and experiencing enhanced effectiveness of opioids; and benzodiazepines having a longer duration of action in women. ${ }^{16}{ }^{17}$ Similar to that reported in other European countries, ${ }^{49}$ Ireland does not have a national prescription drugs monitoring system. Such a system would assist with pharmacovigilance and with identifying and monitoring trends in the misuse of prescription drugs.

The significant increase in deaths involving benzodiazepines in both men and women is of concern. The decreasing rate of benzodiazepines dispensed through the PCRS-GMS system appears to correspond with changes in policy, which introduced stricter prescribing regulations. ${ }^{50}$ However, given the increase in illicit benzodiazepines in the community, as indicated by the increase in seizure data, and reports from experts in the area, ${ }^{51}$ tighter controls on prescribing benzodiazepines may have partially resulted in an increased use of illicit benzodiazepines. These illicit benzodiazepines have higher potency and are available at low cost. ${ }^{52}$ Due to the shorter halflife of illicit benzodiazepines, people who use these drugs tend to take repeated dosages, which increases the risk of a poisoning death.

In Ireland, there were no national guidelines for benzodiazepine maintenance treatment. However, during the COVID-19 pandemic, benzodiazepine maintenance treatment was offered to homeless clients on OAT with established benzodiazepine dependency. ${ }^{53}$ In 2019, $10 \%$ of clients in receipt of treatment for drug use in Ireland reported benzodiazepines as their primary problem drug, while $35 \%$ reported benzodiazepines as an additional problem drug. ${ }^{48}$ While it is unknown what proportion of drug poisoning deaths since 2017 involved benzodiazepines, the United Nations Office on Drugs and Crime $^{54}$ indicated in 2017 that polydrug use, particularly with benzodiazepines, may be linked to the increase in prescription opioid deaths. Misuse of benzodiazepines is a growing public health threat, with benzodiazepines identified as one of the most commonly misused prescription 
drugs. ${ }^{55}$ Given the increasing risk of drug poisoning deaths involving benzodiazepines, continuation of and improved access to maintenance treatment, along with guidelines, and detoxification for people who are known to be misusing or dependent on benzodiazepines should be considered. Research has shown that brief interventions delivered in the primary care setting are effective in both reducing and discontinuing long-term benzodiazepine use. ${ }^{55}$

While it is disappointing to see no significant decrease in deaths involving heroin, the stabilisation of rates for drug poisoning deaths involving heroin may be due to increased access to treatment, and/or it may reflect drug markets or drug use patterns among the population. Of note, prevalence data also indicate a stabilisation in the use of heroin in the population. ${ }^{42}$ It is known that between 2010 and 2011 there was a severe shortage of heroin in the European market, ${ }^{56}$ the reasons for which were multifaceted. In Ireland the heroin drought was reflected in a decrease in heroin poisoning deaths in 2011, but this decrease was counterbalanced by an increase in drug poisoning deaths involving benzodiazepines and methadone. ${ }^{15}$ The heroin drought may be an example of how despite the lack of heroin the underlying substance use disorder did not dissipate. Drug markets influence changing patterns in drug use, so with a decrease in availability of heroin, people who used heroin may have had no alternative but to revert to using other drugs. This was observed in Australia, with an increase in cocaine and methamphetamine use during a period of reduced heroin availability. ${ }^{57} 58$

Internationally there has been a decrease in recent years in the number of new treatment entries for OAT. ${ }^{98}$ However, data from 2018 show a significant increase in heroin seizures in the European Union. ${ }^{9}$ This, in combination with recent evidence from Australia showing an increase in deaths involving heroin, ${ }^{59}$ indicates that heroin remains a main contributor to drug-related harm, including drug poisoning deaths worldwide.

Although beyond the scope of this study, it would be of interest to assess the impact of the codeine dispensing guidelines for non-prescription products containing codeine (introduced in Ireland in 2010), ${ }^{60}$ on drug poisoning deaths involving opioids.

In an effort to prevent drug poisoning deaths among both men and women, a combination of pharmacological, psychosocial and harm reduction interventions, with increasing access to sex-specific and age-appropriate treatment and wider availability of naloxone, should be implemented. ${ }^{61}{ }^{62}$ Promoting more open communication between prescribers and clients should enhance provision of appropriate treatment and help clients make informed decisions about their drug use. Innovative models of virtual healthcare delivery, such as those adapted during the COVID-19 pandemic, could also help minimise barriers to accessing services. Consideration should be given to incorporating this model of care, in addition to face-to-face consultations, in future delivery of treatment. ${ }^{63}$ Services tailored to the particular needs of women are also required, such as increasing the number of residential treatment beds with childcare facilities.

Advocates for people who use drugs should be consulted on and contribute to policy decisions around harm reduction associated with drug use. Policies to reduce drug poisoning deaths should move from a criminal justice focus to a more public health focus. ${ }^{64}{ }^{65} \mathrm{Harm}$ reduction initiatives, along with treatment interventions, which include pharmaceutical combined with psychosocial assistance, need to focus on the range of problematic drugs. Furthermore, reducing stigma associated with drug use and drug poisoning deaths, aligned with actions to target economic deprivation, is required.

Future research in the area of drug poisoning deaths should include stratification by sex. Sex-specific evidence is required to support appropriate policy actions to reduce drug poisoning deaths.

\section{Strengths and limitations}

The main strength of this study is the use of national data validated from a number of sources, ensuring accuracy and completeness of data available to examine trends in drug poisoning deaths by sex. Access to prescription data for prescribed benzodiazepines and antidepressants enabled assessment of the relationship between trends in prescribing for and drug poisoning death rates involving these drugs.

The observation period of 2004-2017 is a strength of this study due to the many years of data included. Due to the nature of the death investigation and data collection processes, more recent data on drug poisoning deaths were not available. Future work will need to assess whether there have been any trend changes since 2017 .

Limitations of this study include the reliance on individual coroners to implicate drugs in poisoning deaths, which can be challenging when multiple drugs are present on a toxicology report. Information on whether the drugs were prescribed to the deceased is frequently not available in coronial files, which limits the assessment of illicit use of these drugs and the impact of illicit drugs on these deaths.

Lack of data on private prescription drugs dispensed limits analysis to those dispensed through the PCRS-GMS scheme, which covers approximately $40 \%$ of the general population. The PCRS-GMS scheme over-represents the more socially deprived and older-aged populations and therefore does not represent the total population use of these drugs. In addition, the lack of data on consumption of other drugs (including prescription opioids, alcohol, cocaine and heroin), stratified by sex, limited the analysis on these drugs.

Clients registered on the national OAT register can remain registered up to 30 days after leaving treatment. Therefore, data on clients in receipt of prescription opioids at the time of their death are incomplete. For this reason we were not able to assess the relationship between dispensing of prescription opioids and deaths involving prescription opioids. 


\section{CONCLUSION}

There is a need for an efficient healthcare response to polydrug use, which should include pragmatic harm reduction information around potentially lethal combinations of drugs, including alcohol, and how to reduce consumption of multiple drugs, especially CNS depressant drugs. Increased awareness of physiological sex differences affecting drug activity is required among both prescribers and people who use drugs. In addition to endorsement of a nationwide ePrescription system, an active national prescription monitoring system would assist in increased pharmacovigilance.

\section{Twitter Ena Lynn @EnaCLynn and Kathleen E Bennett @pharmacoepircsi}

Acknowledgements The authors thank the HSE-PCRS, in particular Irene Rooney, for supplying the PCRS-GMS data. The authors also thank the Coroners Society of Ireland and their support staff, the CTL, HIPE and the CSO for supplying the data to the NDRDI, and the NDRDI research nurses for collecting the data from the coroner sites.

Contributors EL, KEB and GC contributed to the concept and design of the study. $\mathrm{KEB}, \mathrm{EL}$ and SL each had a key role in the acquisition of data. EL undertook the statistical analysis with guidance from KEB and GC. EL was responsible for the writing of the manuscript. KEB, GC and SL provided critical input to drafts of the paper. All authors contributed to the interpretation of data, agree to be accountable for all aspects of the work and approved the final manuscript.

Funding KEB is funded by the Health Research Board in Ireland (RL-15-1579). The Health Research Board sponsored academic registration fees for EL but had no role in the design or execution of this study.

Competing interests None declared.

Patient consent for publication Not required.

Ethics approval The study was approved by the Royal College of Surgeons in Ireland Research Ethics Committee on 1 May 2018 (REC 1542).

Provenance and peer review Not commissioned; externally peer reviewed.

Data availability statement № data are available.

Supplemental material This content has been supplied by the author(s). It has not been vetted by BMJ Publishing Group Limited (BMJ) and may not have been peer-reviewed. Any opinions or recommendations discussed are solely those of the author(s) and are not endorsed by BMJ. BMJ disclaims all liability and responsibility arising from any reliance placed on the content. Where the content includes any translated material, BMJ does not warrant the accuracy and reliability of the translations (including but not limited to local regulations, clinical guidelines, terminology, drug names and drug dosages), and is not responsible for any error and/or omissions arising from translation and adaptation or otherwise.

Open access This is an open access article distributed in accordance with the Creative Commons Attribution Non Commercial (CC BY-NC 4.0) license, which permits others to distribute, remix, adapt, build upon this work non-commercially, and license their derivative works on different terms, provided the original work is properly cited, appropriate credit is given, any changes made indicated, and the use is non-commercial. See: http://creativecommons.org/licenses/by-nc/4.0/.

\section{ORCID iDs}

Ena Lynn http://orcid.org/0000-0002-5360-6650

Gráinne Cousins http://orcid.org/0000-0003-2985-7668

Kathleen E Bennett http://orcid.org/0000-0002-2861-7665

\section{REFERENCES}

1 Shiels MS, Tatalovich Z, Chen Y, et al. Trends in mortality from drug poisonings, suicide, and alcohol-induced deaths in the United States from 2000 to 2017. JAMA Netw Open 2020;3:e2016217.

2 Scholl L, Seth P, Kariisa M. Drug and Opioid-Involved Overdose Deaths - United States, 2013-2017. MMWR: Morb Mortal Wkly Rep 2019;67:1419-27.

3 Seth P, Scholl L, Rudd RA, et al. Overdose Deaths Involving Opioids, Cocaine, and Psychostimulants - United States, 2015-2016. MMWR Morb Mortal Wkly Rep 2018;67:349-58.
4 McCall Jones C, Baldwin GT, Compton WM. Recent increases in Cocaine-Related overdose deaths and the role of opioids. Am J Public Health 2017;107:430-2.

5 Best AF, Haozous EA, Berrington de Gonzalez A, et al. Premature mortality projections in the USA through 2030: a modelling study. Lancet Public Health 2018;3:e374-84.

6 Man N, Chrzanowska A, Dobbins T. Trends in drug-induced deaths in Australia, 1997-2018. drug trends Bulletin series. Sydney National Drug and Alcohol Research Centre; 2019. https://ndarc.med.unsw. edu.au/resource/trends-drug-induced-deaths-australia-1997-2018 [Accessed Sep 2020].

7 Kimber J, Hickman M, Strang J, et al. Rising opioid-related deaths in England and Scotland must be recognised as a public health crisis. Lancet Psychiatry 2019;6:639-40.

8 EMCDDA. European drug report 2014: trends and developments, 2014. Available: https://www.emcdda.europa.eu/publications/edr/ trends-developments/2014_en [Accessed Oct 2020].

9 EMCDDA. European drug report 2020: trends and developments, 2020. Available: https://www.emcdda.europa.eu/publications/edr/ trends-developments/2020 en [Accessed 25 Sep 2020].

10 Jalal H, Buchanich JM, Roberts MS, et al. Changing dynamics of the drug overdose epidemic in the United States from 1979 through 2016. Science 2018;361:6408.

11 Lynn E, Doyle A, Keane M, et al. Drug poisoning deaths among women: a scoping review. J Stud Alcohol Drugs 2020;81:543-55.

12 Tweed E, Miller R, Mathesone C. Why are drug-related deaths among women increasing in Scotland? A scoping of possible explanations. Edinburgh Scottish government; 2018. http://www.gov. scot/publications/drug-related-deaths-women-increasing-scotland9781787810129/ [Accessed Sep 2020].

13 Centers for Disease Control and Prevention. Prescription painkiller overdoses: a growing epidemic, especially among women, 2013. Available: https://www.cdc.gov/vitalsigns/prescriptionpainkillerov erdoses/index.html [Accessed 7 Mar 2020].

14 Corkery JM, Schifano F, Ghodse AH, et al. The effects of methadone and its role in fatalities. Hum Psychopharmacol 2004;19:565-76.

15 Health Research Board. National drug-related deaths index 2008 to 2017 data, 2019. Available: https://www.drugsandalcohol.ie/31275 [Accessed Oct 2020].

16 Algren DA, Monteilh CP, Punja M, et al. Fentanyl-associated fatalities among illicit drug users in Wayne County, Michigan (July 2005-May 2006). J Med Toxicol 2013;9:106-15.

17 Whitley $\mathrm{H}$, Lindsey W. Sex-based differences in drug activity. Am Fam Physician 2009;80:1254-8.

18 VanHouten JP, Rudd RA, Ballesteros MF, et al. Drug Overdose Deaths Among Women Aged 30-64 Years - United States, 19992017. MMWR Morb Mortal Wkly Rep 2019;68:1-5.

19 Osborn E. Deaths related to drug poisoning in England and Wales: 2017 registrations. Statistical Bulletin Office for National Statistics; 2018. https://www.ons.gov.uk/releases/deathsrelatedtodrugpoiso ninginenglandandwales2017registrations [Accessed Oct 2020].

20 Tyrrell EG, Orton E, Sayal K, et al. Differing patterns in intentional and unintentional poisonings among young people in England, 1998-2014: a population-based cohort study. J Public Health 2017;39:e1-9.

21 STROBE Statement. STROBE Statement-checklist of items that should be included in reports of observational studies. Available: https://www.strobe-statement.org/fileadmin/Strobe/uploads/ checklists/STROBE_checklist_v4_combined.pdf [Accessed 30 May 2019].

22 Lynn E, Lyons S, Walsh S. Trends in deaths among drug users in Ireland from traumatic and medical causes, 1998 to 2005. Dublin Health Research Board; 2019. https://www.drugsandalcohol.ie/ 12775/ [Accessed Sep 2020].

23 EMCDDA. Drug-Related deaths (DRD) standard protocol, version 3.2, 2010. Available: https://www.emcdda.europa.eu/html.cfm/ index107404EN.html en [Accessed Sep 2020].

24 Roxburgh A, Pilgrim JL, Hall WD, et al. Accurate identification of opioid overdose deaths using coronial data. Forensic Sci Int 2018;287:40-6.

25 Sinnott S-J, Bennett K, Cahir C. Pharmacoepidemiology resources in Ireland-an introduction to pharmacy claims data. Eur J Clin Pharmacol 2017;73:1449-55.

26 Central Statistics Office. StatBank annual population estimates, 2020. Available: https://statbank.cso.ie/px/pxeirestat/Statire/ SelectVarVal/Define.asp? maintable $=P E A 01 \& P L a n g u a g e=0[$ Accessed 15 Feb 2020].

27 Health Service Executive. Primary care reimbursement service: statistical analysis of claims and payments 2008 to 2017, 2017. Available: https://www.sspcrs.ie/portal/annual-reporting/report/ annual [Accessed 12 Sep 2020]. 
28 Eurostat. Revision of the European Standard Population - Report of Eurostat's Task Force. Luxembourg European Commission; 2013.

29 National Cancer Institute. Joinpoint trend analysis softward, 2020. Available: https://surveillance.cancer.gov/joinpoint/ [Accessed 4 Aug 2020].

30 Lynn E, Cousins G, Lyons S, et al. A repeated cross-sectional study of factors associated with pregabalin-positive poisoning deaths in Ireland. Drug Alcohol Depend 2020;206:107741.

31 Cousins G, Boland F, Barry J, et al. J-Shaped relationship between supervised methadone consumption and retention in methadone maintenance treatment (MMT) in primary care: national cohort study. Drug Alcohol Depend 2017;173:126-31.

32 Sordo L, Barrio G, Bravo MJ, et al. Mortality risk during and after opioid substitution treatment: systematic review and meta-analysis of cohort studies. BMJ 2017;357:j1550.

33 Cousins G, Teljeur C, Motterlini N, et al. Risk of drug-related mortality during periods of transition in methadone maintenance treatment: a cohort study. J Subst Abuse Treat 2011;41:252-60.

34 Durand L, O'Driscoll D, Boland F, et al. Do interruptions to the continuity of methadone maintenance treatment in specialist addiction settings increase the risk of drug-related poisoning deaths? A retrospective cohort study. Addiction 2020;115:1867-77.

35 Evans E, Li L, Min J, et al. Mortality among individuals accessing pharmacological treatment for opioid dependence in California, 2006-10. Addiction 2015;110:996-1005.

36 Kimber J, Larney S, Hickman M, et al. Mortality risk of opioid substitution therapy with methadone versus buprenorphine: a retrospective cohort study. Lancet Psychiatry 2015;2:901-8.

37 Santo T, Clark B, Hickman M, et al. Association of opioid agonist treatment with all-cause mortality and specific causes of death among people with opioid dependence: a systematic review and meta-analysis. JAMA Psychiatry 2021. doi:10.1001/ jamapsychiatry.2021.0976. [Epub ahead of print: 02 Jun 2021].

38 Jarlenski M, Barry CL, Gollust S, et al. Polysubstance use among US women of reproductive age who use opioids for nonmedical reasons. Am J Public Health 2017;107:1308-10.

39 Hassan AN, Le Foll B. Polydrug use disorders in individuals with opioid use disorder. Drug Alcohol Depend 2019;198:28-33.

40 Calcaterra S, Glanz J, Binswanger IA. National trends in pharmaceutical opioid related overdose deaths compared to other substance related overdose deaths: 1999-2009. Drug Alcohol Depend 2013;131:263-70.

41 Affleck W, Carmichael V, Whitley R. Men's mental health: social determinants and implications for services. Can J Psychiatry 2018;63:581-9.

42 National Advisory Committee on Drugs and Alcohol, Northern Ireland, Department of Health. Prevalence of drug use and gambling in Ireland \& drug use in Northern Ireland. Bulletin 1, 2016. Available: https://www.drugsandalcohol.ie/26364/ [Accessed Oct 2020].

43 Norström T, Mäkelä P. The connection between per capita alcohol consumption and alcohol-specific mortality accounting for unrecorded alcohol consumption: the case of Finland 1975-2015 Drug Alcohol Rev 2019;38:731-6.

44 Office of Revenue Commissioners. Excise Receipts by commodity, 2020. Available: https://www.revenue.ie/en/corporate/informationabout-revenue/statistics/excise/receipts-volume-and-price/excisereceipts-commodity.aspx [Accessed 4 Jul 2020].

45 Government of Ireland. Public health (alcohol) act 2018, 2018. Available: http://www.irishstatutebook.ie/eli/2018/act/24/enacted/en/ html [Accessed 14 Sep 2020].

46 Eurostat. General government deficit/surplus: \% of GDP and million Eur, 2020. Available: https://ec.europa.eu/eurostat/databrowser/view/ tec00127/default/table?lang=en [Accessed 23 Sep 2020].

47 Hedegaard H, Spencer MR, Garnett MF. Increase in drug overdose deaths involving cocaine: United States, 2009-2018. NCHS data brief No.384 Centre for Disease Control and Prevention; 2020. https://www.cdc.gov/nchs/data/databriefs/db384-H.pdf
48 O'Neill D, Carew A, Lyons S. Drug treatment in Ireland 2013 to 2019. Dublin Health Research Board; 2020. https://www.drugsandalcohol. ie/32094 [Accessed 19 Sep 2020].

49 Novak SP, Håkansson A, Martinez-Raga J, et al. Nonmedical use of prescription drugs in the European Union. BMC Psychiatry 2016;16:274.

50 Benzodiazepine Committee. Benzodiazepines: good practice guidelines for clinicians. Dublin Department of health and children; 2002. https://www.drugsandalcohol.ie/5349/ [Accessed 27 Sep 2020].

51 Duffin T, Keane M, Millar SR. Street tablet use in Ireland. A Trendspotter study on use, markets, and harms. Dublin ANA Liffey drug project; 2020. https://www.drugsandalcohol.ie/31872/

52 Ryan V. 'Fake' benzos potency fears rise. Irish Medical Times. Available: https://www.imt.ie/news/fake-benzos-potency-fears-rise31-08-2020/ [Accessed 31 Aug 2020].

53 O'Carroll A, Duffin T, Collins J. Harm reduction in the time of COVID-19: case study of homelessness and drug use in Dublin, Ireland. Int J Drug Policy 2021;87:102966.

54 UNODC. Global smart update volume 18: non-medical use of benzodiazepines: a growing threat to public health? 2017. Available: https://www.unodc.org/documents/scientific/Global_SMART Update 2017 Vol 18.pdf [Accessed 13 Jun 2021].

55 Lynch T, Ryan C, Hughes CM, et al. Brief interventions targeting long-term benzodiazepine and Z-drug use in primary care: a systematic review and meta-analysis. Addiction 2020;115:1618-39.

56 EMCDDA. Trendspotter summary report recent shocks in the European heroin market: explanations and ramifications. Lisbon EMCDDA; 2011. https://www.emcdda.europa.eu/scientific-studies/ 2011/trendspotters-report_en

57 Roxburgh A, Degenhardt L, Breen C. Changes in patterns of drug use among injecting drug users following changes in the availability of heroin in New South Wales, Australia. Drug Alcohol Rev 2004:23:287-94.

58 Degenhardt L, Conroy E, Gilmour S. The effect of a reduction in heroin supply in Australia upon drug distribution and acquisitive crime. Br J Criminol 2005;45:2-24.

59 Australian Institute of Health and Welfare. Alcohol, tobacco \& other drugs in Australia, 2020. Available: https://www.aihw.gov.au/reports/ phe/221/alcohol-tobacco-other-drugs-australia/contents/drug-types/ illicit-opioids-heroin [Accessed 3 Sept 2020].

60 The Pharmaceutical Society of Ireland. Non-Prescription medicinal products containing codeine: guidance for pharmacists on safe supply to patients. Dublin The Pharmaceutical Society of Ireland; 2010. www.drugsandalcohol.ie/13191 [Accessed 6 Oct 2020].

61 Fairbairn N, Coffin PO, Walley AY. Naloxone for heroin, prescription opioid, and illicitly made fentanyl overdoses: challenges and innovations responding to a dynamic epidemic. Int J Drug Policy 2017;46:172-9.

62 Degenhardt L, Grebely J, Stone J, et al. Global patterns of opioid use and dependence: harms to populations, interventions, and future action. Lancet 2019;394:1560-79.

63 Crowley D, Delargy I. A national model of remote care for assessing and providing opioid agonist treatment during the COVID-19 pandemic: a report. Harm Reduct $J$ 2020;17:49.

64 EMCDDA. Health and social responses to drug problems: a European guide, 2017. Available: https://www.emcdda.europa. eu/publications/manuals/health-and-social-responses-to-drugproblems-a-european-guide_en [Accessed assessed 20 Sept 2020].

65 UNODC. Treatment and care of people with drug use disorders in contact with the criminal justice system: alternatives to Conviction or punishment, 2016. Available: https://www.unodc.org/unodc/en/ drug-prevention-and-treatment/treatment-and-care-of-people-withdrug-use-disorders-in-contact-with-the-criminal-justice-system_alternatives-to-conviction-or-punishment.html [Accessed assessed Oct 2020]. 